\title{
Analysis of the displacement of geodetic stations during the Emilia seismic sequence of May 2012
}

\author{
Alessandro Caporali ${ }^{\star}$, Luca Ostini
}

Università di Padova, Dipartimento di Geoscienze, Padova, Italy

\author{
Article history \\ Received July 19, 2012; accepted August 22, 2012. \\ Subject classification: \\ Crustal deformations, GPS Geodesy, InSAR, Coseismic deformation.
}

\section{Introduction}

The two events of $\mathrm{M}_{\mathrm{W}} 6.11$ and 5.96 [EMERGEO Working Group 2012, this volume] that took place on May 20 and 29, 2012, respectively, in the Po Plain, and the associated seismic sequence, represent the response of the brittle upper crust (hypocentral depth ca. $10 \mathrm{~km}$ ) to the compressive stress in the outer Apennine Arc. Kinematically, the motion of the Apennines that has led to a compressional regime in the Po Plain can be represented as a counterclockwise rotation, as demonstrated by the shortening of the transalpine baselines, with a rate that decreases going west [Caporali and Martin 2000]. The compressive stress field is known from borehole breakout data [Pierdominici and Heidbach 2012] and it agrees with the principal directions of the strain rate derived from global positioning system (GPS) data. The geodetic strain rate for seismic zone 912 (Dorsale Ferrarese, according to Meletti et al. [2008]) is $92.86 \pm 0.04$ nstrain/yr, which is a relatively high value [Caporali et al. 2011]. On a more local scale, the Mirandola fault is described in the Database of Individual Seismic Sources (DISS; http: / / diss.rm.ingvit/) under the ID ITIS107 as a possible individual source, and it has a position, strike, dip, size and expected maximum magnitude [Burrato et al. 2003, Carminati et al. 2010, Scrocca et al. 2007] that are very close to the main events of the 2012 sequence.

Several permanent GPS stations were in activity in the area. Using ultrarapid international Global Navigation Satellite Systems (GNSS) Service (IGS) orbits and the Bernese BSW 5.0 software [Dach et al. 2007] at our computing facility, a fast solution for the coseismic displacement was published on the May 21, 2012, and on the May 30, 2012, for the events of May 20 and 29, 2012, respectively. The largest signal was about $2 \mathrm{~cm}$ in the North direction at the station SGIP (San Giovanni in Persiceto), which was relatively consistent with the fault-plane solution [Devoti 2012, this volume]. In this study, we present more detailed estimates of the coseismic offsets at several other stations in the area, including a kinematic solution at $30 \mathrm{~s}$ temporal resolution. The coseismic displacements are inverted using the Okada [1985] model and a preliminary model of the two faults is obtained for each of the two main events, taking into account the available synthetic aperture radar (SAR) data.

\section{GPS data}

We compute weekly network solutions for some 150 Italian permanent GPS stations using IGS/EUREF processing standards (http:/ / www.epncb.oma.be/_documentation/ guidelines/guidelines_analysis_centres.pdf). The normal equations that have been available since 1999 are then stacked, minimum constraints are imposed on EUREF Permanent Network (EPN) Class A reference stations, and the time series are generated. The velocity map is updated weekly, which excludes stations with insufficiently long tracking logs [http:/ / 147.162.229.63/scidata/velocity_s.pdf]. This systematic procedure allows the deformation field in the national territory, in the sense of the average regional strain rate, to be continuously monitored and updated. In the case of seismic events, the procedure yields an immediate detection of coseismic offsets. An ad-hoc kinematical solution for selected sites is then run to investigate displacements at high frequency. Figure 1 shows the vertical and horizontal coseismic offsets obtained for the May 20 and 29, 2012, events, and the corresponding time series. In both cases it clearly appears that the stations located south of the epicenters moved north (e.g. MOPS, SGIP), and those north of the epicenter moved south (e.g. LEGN), as would be expected for a reverse fault with strike nearly EW. Based on the routine daily analysis using double differences, we reprocessed selected baselines in kinematic mode, with output at $30 \mathrm{~s}$. The tropospheric parameters and the ambiguities obtained in the daily processing were back-substituted into the kinematic solution, and $30 \mathrm{~s}$ estimates of the coordinates of selected stations were obtained in a time window centered on the events of May 20 and 29, 2012. To minimize effects of multipath and satellite geometry, the computation was repeated for the 

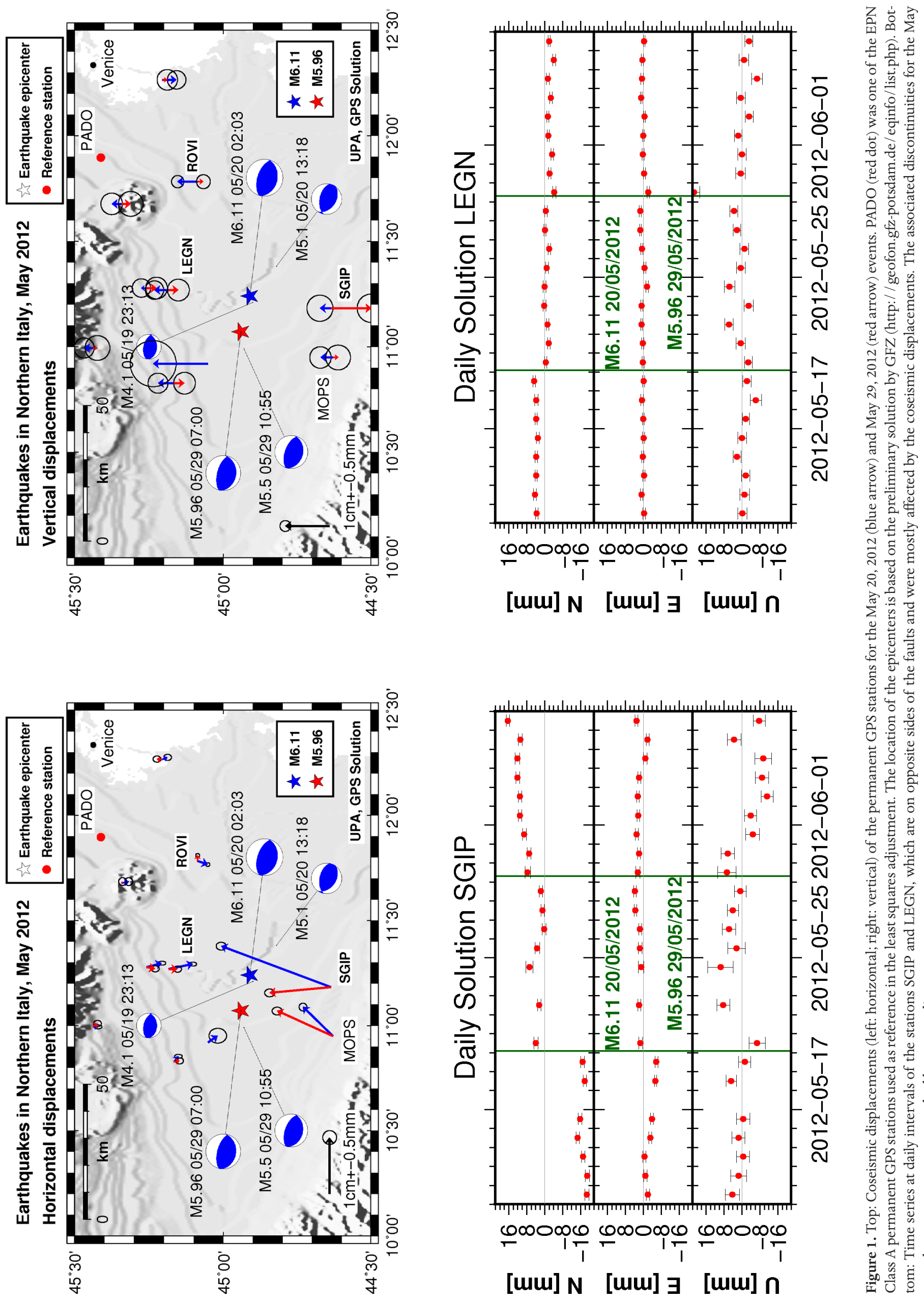

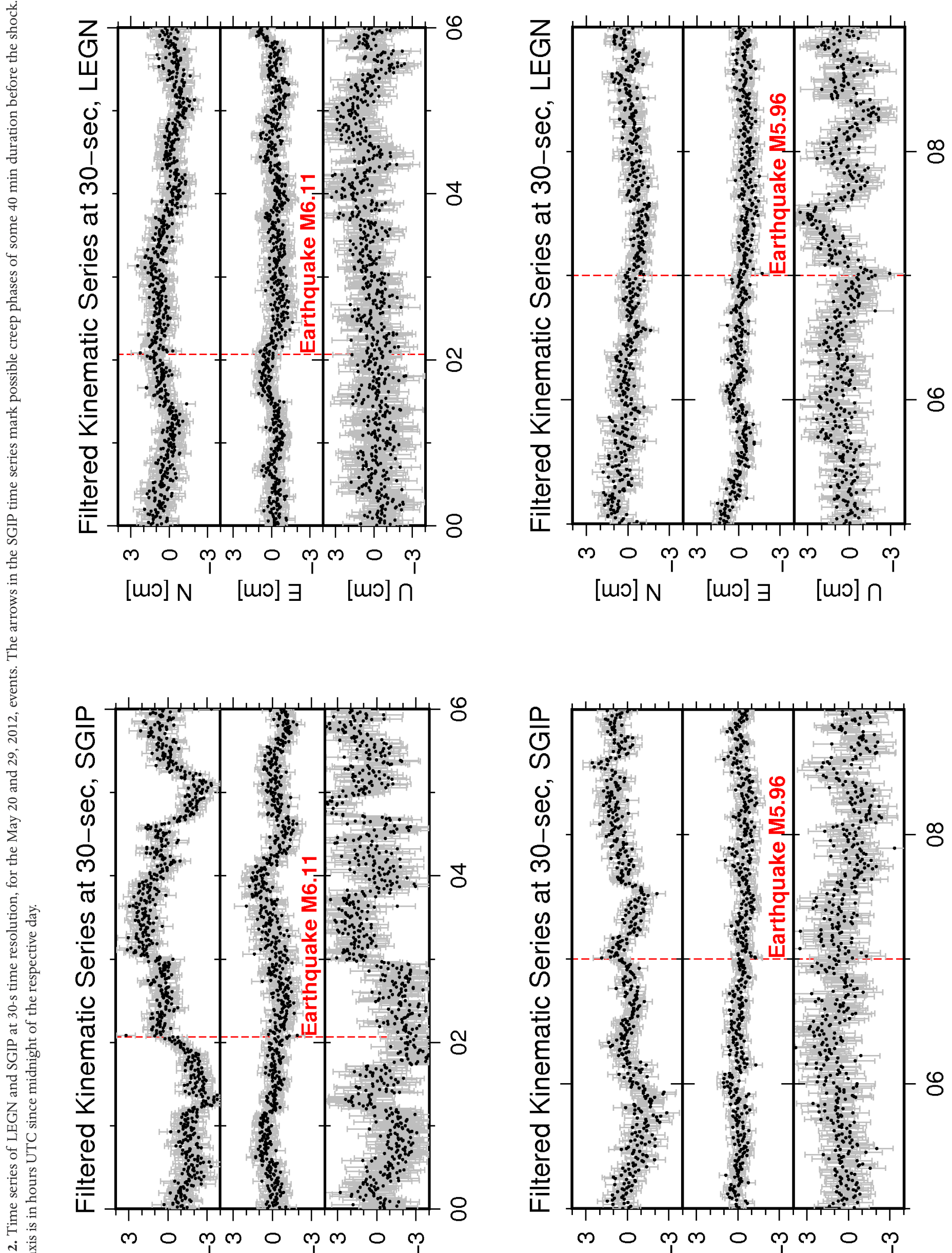

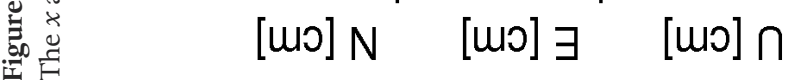
[wo $N \quad[$ $N] \exists[\omega 0] \cap$ 
same time window one day earlier, with the same baselines and satellites, which generated a reference time series that was not affected by the seismic motion, but with very similar systematic effects related to the satellite geometry and multipath [Bock 1991, Choi et al. 2004]. These time series, shifted by $3 \mathrm{~min} 56 \mathrm{~s}$, were subtracted from the time series centered at the epochs of the two seismic events, which resulted in a mitigation of high and low frequency noise (sidereal filter). Figure 2 shows the time series of stations SGIP and LEGN after the removal of the common noise. The high frequency changes of the nominal coordinates that were visible in the unfiltered time series are now removed, but it is as yet too early to conclude whether they are a geophysical signal or they are noise. The ramp in the north component of station SGIP on May 20 and 29, 2012, is very clearly resolved. We speculate a sort of creep movement that initiated roughly $40 \mathrm{~min}$ before the respective shocks, but evidence based upon such small amounts of data cannot be claimed.

\section{Modeling}

To model the GPS data, we used the Coulomb 3.20 software developed by the U.S. Geological Survey [Lin and Stein 2004, Toda et al. 2005], complemented with a module for numerical computation of partial derivatives, set-up for the normal equations and parameter adjustment by weighted least squares. The data available for the inversion are unfortunately few. The first check we did was to verify that a source model was relatively compatible with the observed horizontal displacements of the GPS stations. This was based on the published fault-plane solution, on the empirical relations of Wells and Coppersmith [1994], and on the data published in the DISS for the Mirandola fault. We tested the option of north-verging faults, although it appears most logical from the geological sections that southverging faults are more likely.

The fault in both events was initially considered a rectangle of length $(\mathrm{L}) \times$ width $(\mathrm{W})$ of $12 \times 9 \mathrm{~km}$, with an in-plane slip of $0.5 \mathrm{~m}$, mostly in the reverse (up-dip) direction. This yielded a seismic moment of $1.62 \times 10^{18} \mathrm{Nm}$, or $\mathrm{M}_{\mathrm{W}} 6.07$, assuming ( $\mu=30 \mathrm{GPa}$ ). However, the publication of the InSAR data based on the Radarsat 1 and, in part, the Cosmo Skymed satellites [Salvi et al. 2012, this volume] made it clear that the structures of both faults, and particularly the May 29, 2012, event, were somewhat different from that implied by the seismological data. In addition, a rather large uplift of some 0.12 $\mathrm{m}$ was reported in the central parts of the faults, which would have been incompatible with the original model, and in particular with a slip of only $0.5 \mathrm{~m}$.

We constrained the seismic moment to be equal to the seismologically derived value and started to investigate an alternative source model, with smaller $\mathrm{L}$ and $\mathrm{W}$, and a slip in the range of $0.7 \mathrm{~m}$ to $0.9 \mathrm{~m}$. The result is described in Figure 3 (right), which shows that the GPS data that is intended as the sum of the displacements of the May 20 and 29, 2012, events, still fits this new model. The vertical uplift along the strike of the two faults is consistent with that obtained from the InSAR data. The epicenters of the two main events, however, do not coincide with the centers of the faults, but are slightly offset to the east (May 20) and to the west (May 29). The measured GPS displacements are systematically larger than the computed ones, perhaps due to monument instability, although in the same direction. Figure 3 (right) also shows how the reverse faulting of the May 2012 events is consistent with the deformation regime implied by long-term GPS data. The solutions independently presented in this volume by Bignami et al. [2012] and Serpelloni et al. [2012] appear qualitatively consistent with our proposed, preliminary solution.

\section{Conclusion}

The geodetic data available for the Emilia 2012 seismic sequence are few but valuable, in that they can discriminate displacements attributable to the individual events of May 20 and May 29, 2012. The InSAR data are also of moderate quality. The Radarsat 1 interferogram refers to the combined events, and the Cosmo Skymed only to the event of May 29. Merging the GPS and SAR datasets appears to fill the mutual gaps and enables a reasonable source model to be outlined. Taking into account the available information on the InSAR and CMT solutions, we conclude that the data are consistent with the elastic model defined in Table 1.

\begin{tabular}{|c|c|c|c|c|c|c|c|c|c|c|}
\hline \multicolumn{2}{|c|}{ Coordinates } & \multicolumn{2}{|c|}{ Slip } & \multirow{2}{*}{$\begin{array}{l}\text { Dip } \\
\left(^{\circ}\right)\end{array}$} & \multirow{2}{*}{$\begin{array}{l}\text { Strike } \\
\left({ }^{\circ}\right)\end{array}$} & \multicolumn{3}{|c|}{ Rectangular fault } & \multirow[t]{2}{*}{$\mathbf{M}_{\mathrm{W}}$} & \multirow{2}{*}{$\begin{array}{c}\text { Date } \\
\text { (ddmmyyyy) }\end{array}$} \\
\hline $\begin{array}{l}\text { Longitude } \\
\quad\left({ }^{\circ} \mathrm{E}\right)\end{array}$ & $\begin{array}{l}\text { Latitude } \\
\qquad\left({ }^{\circ} \mathbf{N}\right)\end{array}$ & $\begin{array}{c}\text { Right lateral } \\
(\mathbf{m})\end{array}$ & $\begin{array}{c}\text { Reverse } \\
\text { (m) }\end{array}$ & & & $\begin{array}{c}\text { Depth of } \\
\text { lower corner } \\
(\mathrm{km})\end{array}$ & $\begin{array}{l}\text { Length } \\
(\mathrm{km})\end{array}$ & $\begin{array}{l}\text { Width } \\
(\mathbf{k m})\end{array}$ & & \\
\hline 11.35 & 44.83 & 0.19 & 0.85 & 35 & 118 & 12 & 10 & 6 & 6.06 & 20052012 \\
\hline 11.20 & 44.83 & 0.12 & 0.70 & 35 & 91 & 11 & 9 & 6 & 5.97 & 29052012 \\
\hline
\end{tabular}

Table 1. Central coordinates and characteristics of the rectangular faults, with implied moment magnitude for the two main events, assuming a shear modulus $\mu=30 \mathrm{GPa}$. The 1 formal uncertainties are $0.05^{\circ}$ for the geographical coordinates, $0.05 \mathrm{~m}$ for the slip vector, $3^{\circ}=$ for the dip and strike angles, $2 \mathrm{~km}$ for the depth, length and width. 

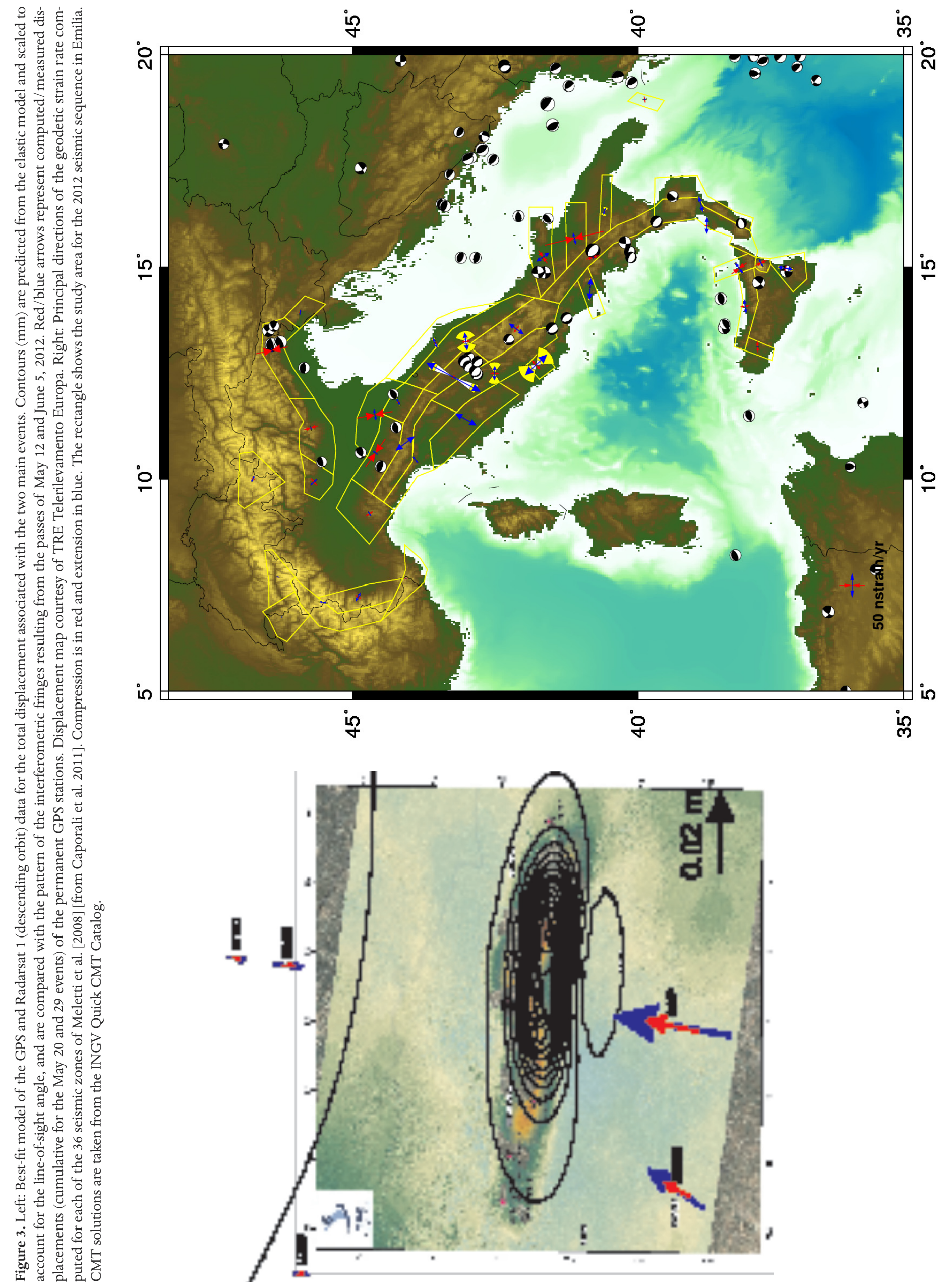
Acknowledgements. This study is supported by a Research Grant from the University of Padova entitled Monitoring from space and interpreting surface deformations in seismic areas. We are grateful to Ufficio Cartografico of Regione Veneto for the support to the stations of the Permanent GPS Network used in this study. We thank Dr. A. Ferretti and Ms. S. Del Conte for kindly making available the georeferenced InSAR displacement maps of Radarsat 1. We thank Dr. A. Ganas and an anonymous Reviewer for valuable comments which helped to improve the first draft of the manuscript.

\section{References}

Bignami, C., P. Burrato, V. Cannelli, M. Chini, E. Falcucci, A. Ferretti, S. Gori, C. Kyriakopoulos, D. Melini, M. Moro, F. Novali, M. Saroli, S. Stramondo, G. Valensise and P. Vannoli (2012). Coseismic deformation pattern of the Emilia 2012 seismic sequence imaged by Radarsat-1 interferometry, Annals of Geophysics, 55 (4); doi:10.4401/ag-6157.

Bock, Y. (1991). Continuous monitoring of crustal deformation, GPS World, 2 (6), 40-47.

Burrato, P., F. Ciucci and G. Valensise (2003). An inventory of river anomalies in the Po Plain, Northern Italy: evidence for active blind thrust faulting, Annals of Geophysics, 46 (5), 865-882.

Caporali, A., and S. Martin (2000). First results from GPS measurements on present day alpine kinematics, J. Geodyn., 30 (1-2), 275-283

Caporali, A., S. Barba, M.M.C. Carafa, R. Devoti,G. Pietrantonio and F. Riguzzi (2011). Static stress drop as determined from geodetic strain rates and statistical seismicity, J. Geophys. Res., 116, B02410; doi:10.1029/2010JB007671.

Carminati, E., D. Scrocca and C. Doglioni (2010). Compaction-induced stress variations with depth in an active anticline: Northern Apennines, Italy. J. Geophys. Res., 115, B02401; doi:10.1029/2009JB006395.

Choi, K., A. Bilich, K.M. Larson and P. Axelrad (2004). Modified sidereal filtering: Implications for high-rate GPS positioning, Geophys. Res. Lett., 31, L22608; doi:10.1029/ 2004GL021621.

Dach, R., U. Hugenthobler, P. Friedez and M. Meindl (2007). Bernese GPS Software Version 5.0, Astronomical Institute, University of Bern, $612 \mathrm{pp}$.

Devoti, R. (2012). Combination of coseismic displacement fields: a geodetic perspective, Annals of Geophysics, 55 (4); doi:10.4401/ag-6119.

EMERGEO Working Group (2012). Technologies and new approaches used by the INGV EMERGEO Working Group for real-time data sourcing and processing during the Emilia Romagna (northern Italy) 2012 earthquake sequence, Annals of Geophysics, 55 (4); doi:10.4401/ag-6117.

Lin, J., and R.S. Stein (2004). Stress triggering in thrust and subduction earthquakes, and stress interaction between the southern San Andreas and nearby thrust and strikeslip faults, J. Geophys. Res., 109, B02303; doi:10.1029/ 2003JB002607.

Meletti, C., F. Galadini, G. Valensise, M. Stucchi, R. Basili, S. Barba, G. Vannucci and E. Boschi (2008). A seismic source model for the seismic hazard assessment of the Italian territory, Tectonophysics, 450, 85-108.

Okada, Y. (1985). Surface deformation due to shear and tensile faults in a half-space, B. Seismol. Soc. Am., 75, 11351154.

Pierdominici, S., and H. Heidbach (2012). Stress field of Italy - Mean stress orientation at different depths and wavelength of the stress pattern, Tectonophysics, 532-535, 301311; doi:10.1016/j.tecto.2012.02.018.

Salvi, S., C. Tolomei, J.P. Merryman Boncori, G. Pezzo, S. Atzori, A. Antonioli, E. Trasatti, R. Giuliani, S. Zoffoli and A. Coletta (2012). Activation of the SIGRIS monitoring system for ground deformation mapping during the 2012 Emilia seismic sequence, using COSMO-SkyMed InSAR data, Annals of Geophysics 55 (4); doi:10.4401/ag-6181.

Scrocca, D., E. Carminati, C. Doglioni and D. Marcantoni (2007). Slab retreat and active shortening along the Central-Northern Apennines, In: O. Lacombe, J. Lavé, F. Roure and J. Verges (eds.), Thrust belts and Foreland Basins. From Fold Kinematics to Hydrocarbon Systems, Frontiers in Earth Sciences, Springer, 471-487.

Serpelloni, E., L. Anderlini, A. Avallone, V. Cannelli, A. Cavaliere, D. Cheloni, C. D'Ambrosio, E. D'Anastasio, A. Esposito, G. Pietrantonio, A.R. Pisani, M. Anzidei, G. Cecere, N. D'Agostino, S. Del Mese, R. Devoti, A. Galvani, A. Massucci, D. Melini, F. Riguzzi, G. Selvaggi and V. Sepe (2012). GPS observations of coseismic deformation following the May 20 and 29, 2012, Emilia seismic events (northern Italy): data, analysis and preliminary models, Annals of Geophysics, 55 (4); doi:10.4401/ag-6168.

Toda, S., R.S. Stein, K. Richards-Dinger and S. Bozkurt (2005). Forecasting the evolution of seismicity in southern California: Animations built on earthquake stress transfer, J. Geophys. Res., 110, B05S16; doi:10.1029/2004JB003415.

Wells, D.L., and K.J. Coppersmith (1994). New empirical relationships among magnitude, rupture length, rupture width, rupture area, and surface displacement, B. Seismol. Soc. Am., 84, 974-1002.

\footnotetext{
${ }^{\star}$ Corresponding author: Alessandro Caporali, Università di Padova, Dipartimento di Geoscienze, Padova, Italy; email: alessandro.caporali@unipd.it.
}

(C) 2012 by the Istituto Nazionale di Geofisica e Vulcanologia. All rights reserved. 